\title{
Bridging The Gap Between Higher Education And The Workforce: A Coach Approach To Teaching
}

\author{
Hayley Hesseln \\ Saskatchewan, Canada
}

\author{
Janice Gair \\ Manitoba, Canada
}

\begin{abstract}
There is debate in the business community around whether new entrants to the labour market are as proficient in essential skills such as communications, collaboration, and critical thinking as were their forbears. At the same time, the demand for executive coaching has increased substantially under both strong and weak economic conditions. Corporations are now using coaching to enhance essential skills within the workplace, which gives rise to questions about college graduates' skills and the positive impact coaching skills could have if embedded within academia. We explore the benefits of using a coach approach in the classroom whereby the instructor engages, enlightens, and empowers students to better prepare graduates for life-long learning and the labour market. The model requires the instructor to embrace authenticity, insight, and innovation by taking a coach approach to teaching with the intent to enhance learning outcomes.
\end{abstract}

Keywords: experiential learning, life-long learning, communication, pedagogy, critical thinking

\section{Introduction}

There is growing concern that many university postsecondary graduates entering the labour market are lacking essential skills related to communications, collaboration, and critical and creative thinking (Jandciu et al., 2015; Laud and Johnson 2013). The corporate sector is increasingly reporting that graduates are not prepared and do not have proficiency in jobrelated skills (e.g. Brown, 2016; Dishman, 2016; Wicks, 2016). A report by the Canada West Foundation revealed that $30 \%$ of college graduates do not have the essential skills necessary to complete their work (Lane and Murray, 2015). Additionally, data from PayScale (2016), a company that specializes in 
job statistics, reports how managers rate the skills gap. The greatest gap was seen in critical thinking/problem solving (60\%), followed by attention to detail (56\%), communication (46\%), ownership (44\%), leadership (44\%), and writing proficiency (44\%); percentages indicate the proportion of managers that selected each skill as lacking.

Over the same period, the demand for executive coaching has increased substantially. A survey by the American Management Association in 2008 revealed that $52 \%$ of respondents were using coaching and that $37 \%$ of those not using coaching were planning to in the future (Thompson et al., 2008). Corporations have identified the need to develop softer skills (Sabatier, 2015) and are using coaching to enhance communication and collaboration skills, mindfulness and critical thinking, and a greater focus on responsibility and accountability. Corporations that have established a coaching culture report that employees exhibit greater job satisfaction, lower turnover resulting in lower search costs, and ultimately greater productivity (Lane and Murray, 2015).

While the use of executive coaching has become increasingly popular over the past decade, the industry is also getting greater demand from senior executives and management. According to the Harvard Business Review (Coutu and Kauffman, 2009), 48\% of business coaches were hired to develop highpotential staff members or facilitate a transition of position, such as manager to leader. The International Coach Federation tracks the effects of executive coaching in corporations. Research reveals that age is an important predictor of consumer awareness and participation in coaching; the younger demographic will engage in coaching services more readily, which will be important as the next generation moves into leadership roles (PriceWaterhouseCoopers, 2014).

Considering the declining skills in postsecondary graduates, and the increasing need for coaching in the workplace, we ask why coaching is not introduced at the postsecondary level. Universities have a long history of using the classic lecture format whereby students gather round the "expert" to listen and learn, generally in large classroom settings. While educational delivery has been changing with the increasing use of problem-based learning and experiential learning, for example, there remains the need for further development. Building on experiential learning, we suggest that adopting a coach approach to teach university and college classes, particularly in those fields that embrace "training" as part of their mandate (e.g. business, 
medicine, engineering, and vocational colleges), will foster better engagement and help to narrow the skills gap.

This paper explores the benefits of using a coach approach in the classroom whereby the instructor that focuses on engagement, enlightenment, and empowerment to enhance students' performance can better prepare university graduates for the labour market. More specifically a coach approach in the classroom is founded on the belief that the student is the expert regarding his or her learning needs and ability and that the instructor will create an atmosphere that fosters trust, provides opportunities for exploration and discovery, and adds value to the learning experience beyond the classroom by focusing on development of essential skills and lifelong learning. The model requires the instructor to embrace authenticity, insight and innovation by taking a coach approach to teaching, creating engagement in the classroom and empowering and enlightening students more effectively.

\section{Model for coaching in the classroom: a two-pronged approach}

In this section we propose a model to enhance teaching effectiveness, promote life-long learning, and ensure that students not only learn the theoretical aspects of the subject matter, but the essential skills necessary to meet objectives when in the workforce. The approach is two-pronged in that (1) the instructor must embody a coach approach, and (2) students must acquire essential skills as they move through academia and into the workforce.

\section{The lecturer as coach}

Using a coach approach in the classroom requires that the lecturer (university teachers or faculty members) embody four dimensions of leadership - authenticity, insight, innovation, and coaching (see Černe et al., 2013; Ashkanasy and Tse, 2000). To effectively apply the coach approach to the classroom, it is essential to present in an authentic manner, to provide insight into the importance of the curriculum, to use innovative techniques that will embed the learning, and finally, to coach students to take ownership and responsibility for their own growth.

Authenticity in its simplest form is about truthfulness and sincerity of intentions and features centrally in the practice of coaching as fundamental to establishing trust. In the classroom, authenticity is about being sincere as to 
expectations of the students, expectations of the lecturer, and being committed to helping students achieve their academic goals. The literature discusses authenticity in academia as the authentic creation of knowledge through scholarship (Newman et al., 2007; Newman and Wehlage, 1993), and the much-less-studied approach that examines the effects of the authenticity of the lecturer on learning (Kreber, 2013; Kreber and Klampfleitner, 2012). While both are important from a teaching perspective, and both are essential in terms of scholarship, it is the latter upon which we focus here.

The instructor that embodies authenticity will serve as a role model to provide fair and honest feedback to each student and to create an atmosphere of trust to foster learning. Authenticity requires that the learner, rather than the instructor, become the focus of the classroom. This is also known as "student-centred" or "differentiated" learning (for examples, see Greener, 2015). To that end, authentic teaching requires instructors to not only deliver the curriculum, but to engage with students to determine how they learn, how best to create experiences that generate positive learning outcomes, to fairly and transparently assess students, and to ensure that scholarly material is relevant beyond the classroom. At the same time, student achievements will be authentic when intellectual accomplishments are worthwhile, significant, and meaningful (Askew, no date).

A leader who possesses insight is someone who shares a purpose and clear vision for the future, and inspires those around them to accomplish more than they had thought possible. Insight in the classroom is particularly important to ensure that students embrace the purpose of the curriculum and its importance in terms of application and relevance to their future. An insightful lecturer will intuit whether students are engaged and be perceptive to each individual's ability to learn and apply new concepts. Instructors who are insightful also are able to impart the importance of vision to their students thus enabling graduates to understand and see the "bigger picture." Being aware of these aspects and taking time to articulate them at the beginning of a course is important to set the tone for the classes to follow.

Providing insight into the deeper meaning and application of scholarly material encourages the student to see the direct purpose of academic curricula in their own world - where they work, how they live, and how lessons can benefit their future. For example, Hesseln teaches economics to many students with farming backgrounds. When students are asked to interpret economic concepts such as demand and supply, using farming 
examples with producers and shoppers makes the theories relevant. Encouraging students to envision how to apply scholarship in a manner that suits each student should ensure longer-term retention because of heightened relevance. Lord (2007) tested this theory as a repeated experiment to assess the "cone of learning" originally proposed by E. Dale in 1969. Results showed that the manner in which information was delivered mattered to learning outcomes and longer-term retention. Finally, insightful lecturers lead by example and can instill the importance of seeking deeper meaning and thoughtful application to classroom lessons.

Leadership skills in the classroom require innovation. To use a coach approach, lectures must be innovative, and lecturers must be engaged and provide insights that explain "why." The innovative classroom doesn't necessarily have to follow the standard lecture format complete with midterm, final, and one or two assignments. The innovative classroom can employ a variety of assessment techniques that are about discovery, letting the students lead, and student-led projects to promote continuous learning for both the lecturer and the student. The belief in coaching is that the client is fully capable of solving problems or discovering what best suits them. While in an academic setting it is important to teach the theory, with clear guidance, the student must take responsibility to learn the theory, which can be supported through coaching.

There have been significant efforts to develop innovative pedagogical methodologies at the post-secondary level including approaches such as experiential learning (Kolb, 2014) and problem-based learning (Savery and Duffy, 1995). Experiential learning according to Kolb (1984) requires that the student be willing to actively participate in the experience, be able to reflect on the experience, possess and use analytical skills to conceptualize what they've learned, and have the skills necessary to engage in problem solving and decision making.

Taking a coach approach to teaching enhances traditional forms of experiential learning by refocusing the role of the instructor and expanding the learning outcomes beyond the experience. When the instructor takes on the role of coach, he or she creates and shapes the learning experience through engagement, enlightenment and empowerment. Additionally, the instructor as coach ensures that students enhance their essential skills including communication, collaboration, critical and creative thinking, and commitment, as part of the experience. Finally, the instructor as coach leads by example imparting the value beyond the classroom of "how" to show up in 
an authentic manner. As society progresses through the digital age, technological advancements provide a plethora of new media and platforms to disseminate information. While technology is important and can expand how we communicate, it remains the case that for effective learning the lecturer must demonstrate strong leadership capabilities that include coaching skills.

The coach approach to teaching embodies the three dimensions of leadership discussed above, and can be further enhanced when the instructor relinquishes control of the lessons to let the students learn, understanding that not all students will learn the same lessons. Evaluation shifts from testing the students' knowledge based on their memory of facts to a student demonstrating his or her ability to communicate clearly in a variety of forms and forums, solving problems individually and collectively, and through commitment to continued learning by addressing mistakes (which requires the chance to improve upon their work). The student is responsible for participating and is aware of expectations as set out at the beginning of the course.

The classroom coach approach places trust in the student to learn and, when effectively adopted, can transfer accountability from the teacher to the learner. Effective coaching in the classroom also builds up mentorship to the students as a means to support their academic growth with the intent to enable students to reach their highest levels of performance. Ultimately, when the lecturer acts as coach, the responsibility for learning is transferred to the student.

\section{The student as client}

Three coaching elements are essential for success in the classroom including (1) engagement, (2) enlightenment, and (3) empowerment. When these elements are successfully used, the lecturer as coach will set the stage for students to excel. ${ }^{1}$ Coaching in the classroom requires that the lecturer embody a leadership role and embrace a coach approach with individual learners and the class as a whole.

\footnotetext{
${ }^{1}$ This section is based on the "Excelerator" coaching model developed by Essential Impact (www.essentialimpact.com).
} 
Engagement is essential to coaching and is reflected within the 11 core competencies defined by the International Coach Federation (ICF, 2016). Engagement between coach and client sets the foundation for trust and the ability of the coach to learn deeply about the client, and ultimately, to empower the client to design actions and to achieve goals. According to Whittington (2010), transformation occurs "when individuals engage with each other in such a way that the leader and follower raise one another to higher levels of motivation and morality" (p. 18). In the classroom, engagement creates an atmosphere of trust between the lecturer and students, which can promote risk taking by the students, and greater willingness to learn. It is abundantly clear when a lecturer does not engage with the class, but rather lectures to it. The expected outcome shifts from learning and inquiry to memorization and regurgitation.

There is an extensive literature dating back to the 1930s that positively relates student engagement with higher learning outcomes. Pike et al. (2011) provide a synopsis of the literature on college classroom engagement and further reinforce the importance of the concept by looking at learning communities where a cohort of students takes two or more courses based on a common theme. Their results indicate that participation in learning communities boosts student engagement, which then leads to stronger learning outcomes.

Kuh (2003) clearly articulates the importance of engagement in the classroom and its long-term implications for developing essential skills and bridging the gap between postsecondary education and the workforce:

\footnotetext{
The engagement premise is deceptively simple, even self-evident: The more students study a subject, the more they learn about it. Likewise, the more students practice and get feedback on their writing, analyzing, or problem solving, the more adept they become. The very act of being engaged also adds to the foundation of skills and dispositions that is essential to live a productive, satisfying life after college. (p. 25)
}

While creating an engaging classroom certainly is more work, it is more rewarding for both instructor and student, and results in increased attainment of learning outcomes. It also prepares graduates to be engaged in the workforce, which leads to greater workplace satisfaction. For example, Bakker (2011) examines the effects of engaged employees and finds that they are "physically, cognitively, and emotionally connected with their work roles. They feel full of energy, are dedicated to reach their work-related goals, and are often fully immersed in their work" (p. 268). The degree of work 
engagement also leads to higher job performance, and ultimately higher occupational well-being for both the organization and the employee.

Finally, there is a strong link between employee engagement and coaching cultures. A study by the Human Capital Institute (2014) found that organizations that created coaching cultures increased employee engagement from $45 \%$ to $60 \%$. They also note the strong benefits of engagement in the workforce. Given the positive relationships between engagement and learning, and engagement and coaching, it is evident that engagement in the classroom is an important conduit for success between postsecondary education and workforce satisfaction and productivity.

Enlightenment in coaching refers to the transition a client makes as a result of discovery: becoming enlightened as to a problem and to fully comprehend its source, or enlightened about an opportunity. Enlightenment in the classroom has traditionally meant a student's comprehension or satisfactory grasp of the materials being presented. However, student enlightenment should go far beyond the academic and include broader educational goals related to essential skills. An enlightened student not only can master the scholarly material presented as part of the curriculum, but also can effectively communicate its application and importance. An enlightened student can make the scholarly leap from academic programs to where job training is a focus of the labour market. An enlightened student will also be able to teach others and to lead by example as an authentic and innovative individual.

Empowerment has many different definitions and shows up in the scholarly literature largely in relation to assisting marginalized individuals to overcome barriers. The term refers to the degree of authority and autonomy one has to govern their affairs. The psychological literature associates empowerment with Julian Rappaport, who in 1981 examined the paradox of social problems. His take on empowerment is the essence of what a coach approach is about:

Social problems, paradoxically, require that experts turn to nonexperts in order to discover the many different, even contradictory, solutions that they use to gain control, find meaning, and empower their own lives. From such study, which will require genuine collaboration fuelled by a sense of urgency, we may be able to help develop programs and policies that make it possible for others to find niches for living and gain control over their lives. (Rappaport, 1981, p. 21) 
Empowering students in the classroom is about providing them with the tools to ultimately put into practice what they've learned. This includes knowledge transfer as well as the processes by which to operationalize lessons learned. Empowering students can be achieved using a variety of pedagogical approaches including service learning (see Jacoby, 2003; Munter, 2002) and participatory learning (see Hisschemöller and Cuppen, 2015).

Singh et al. (2014) define empowerment from cultural, psychological and structural perspectives, explaining the degree to which individuals feel like they have power, authority, and/or responsibility. When individuals are empowered, they are likely to be more motivated in their tasks, and feel that their needs have been met. Empowering students in the classroom can help to ensure that their academic needs will be met, but, more importantly, it can provide students with the authority and motivation over their own learning. Kirk et al. (2016) demonstrated the importance of empowerment showing that highly empowered students achieved better grades, and are more engaged outside of the classroom.

\section{Coaching in the clasdroom - anecdotal results}

Hesseln is a certified executive coach and an associate professor at the University of Saskatchewan in the College of Agriculture and Bioresources. Using a coach approach to teach economics has provided her with the opportunity to observe the positive effects of a coach approach on student learning. While we have not yet conducted experimental research in this regard, anecdotal evidence suggests that engaging with students, empowering them to take control of their own learning, and enlightening them to the possibilities beyond the classroom results in more effective and meaningful learning.

Her undergraduate 200-level course is structured to accommodate students' interests while delivering the curriculum as specified by university standards. Engagement is the focus of every class period and focuses on building rapport between the lecturer and the student body, the lecturer and individual students, and among the students themselves. Using a coach approach requires open communication, classroom engagement, and activities and assignments designed to enlighten and empower students while at the same time strengthening essential skills. 
Expectations for each class and the course as a whole were clearly articulated in the first meeting. This included expectations about what learning is, how learning is accomplished, and the recognition that different students learn in different ways. To demonstrate open communication, the students were encouraged to articulate their expectations for the course including what they expected to learn, why it was important to them and how they might use the material in the future. Finally, the class discussed responsibilities of both parties - what students could expect from Hesseln and what Hesseln could expect from the students.

Course materials were delivered using experiential and problem-based learning techniques that gave students multiple opportunities to absorb and interpret theoretical concepts, and to apply lessons learned in both group and individual settings, and in oral and written formats. Students were empowered to take charge of their own learning: they selected topics of interest, they demonstrated the applicability of lessons learned to their expected future endeavours (likely employment opportunities, for example), and they were encouraged to make decisions autonomously. To support their learning, Hesseln provided guidance by demonstrating clearly what was required of them, how they could accomplish their tasks, and how they could improve in the future by leveraging their strengths and addressing weaknesses.

While the curriculum is set, there is flexibility in how lessons are imparted. According to Kolb's (1984) requirements for experiential learning, students are given the academic tools to be able to make decisions, to critically analyze academic materials, and to solve problems. The coach approach focuses on increasing their willingness to participate, their ability to engage, and provides them with periods to reflect on what they learned, how they learned it, and what matters to them.

There are many activities available to enrich learning outcomes and to provide students opportunities for individual and group discovery. Objectives for the course included learning the economic material as well as enhancing essential skills. The following provides a brief example of what Hesseln used in her 200-level course:

Think/pair/share - the instructor poses a question based on the learning materials and each student is given a minute or two to think about the answer and to write it down. Students are then paired and must explain their responses to each other. Finally, student pairs are invited to share their response to the class as a whole for discussion. 
Class article reviews - a newspaper article is distributed to each student who then evaluates it and makes an assessment. The students pair up or form small groups for further analysis and explanation to help each other interpret the materials. Finally, groups share their results and respond in the broader classroom format.

Individual writing/peer review/rewriting - students have short writing assignments that they turn in to the instructor. Each assignment is redistributed for peer review including review guidelines. Reviews are returned to students for reflection and revision before final papers are submitted.

Team debates -students and the instructor brainstorm a suite of topics to debate in groups. Students suggest the topics according to their interests and are then invited to choose their top three. Based on selections, students are grouped into triads and must debate for or against the proposition. Students not debating are given the opportunity to question debaters and to vote for the team with the strongest arguments.

Wiki research - teams of students are required to create wiki pages similar to those on Wikipedia that demonstrate research ability of a topic selected by the students. They are invited to be creative and present materials to the rest of the class, who are invited to comment. Students on each wiki team must then respond to comments.

What/so what/what now? - students are asked after each class or section what they learned, what about the lesson mattered, and what they can do with the material.

The activities listed above exemplify the coach approach, which leads to student enlightenment through self-discovery and enables students to identify for themselves how they can excel. Ultimately, students are able to articulate their vision beyond academia. Finally, the following are examples of students' responses to the question, "What did you learn?" posed on a final exam in a 200-level introductory agricultural economics class offered in 2016 that used each of the activities listed above.

Classroom knowledge is useless if it is not taught in a way that connects it to the real world. In this class we learned a great deal about how to take our knowledge and apply it outside of the classroom

We have learned to take a step back and look at things from a broader point of view, to look at things without any preconceived notions. And maybe most importantly we have learned to give both sides of an argument a chance before we decide which side we will support. 
The time I have put into this class has definitely helped me understand what the workforce may consist of, and I have gained insight on a wide variety of agricultural topics that will be important for many years to come.

I have furthered my knowledge in how the economy works, how many factors affect sustainability and how important each of them are...

Going even further, I have worked with my classmates on two different projects, spoken in front of my classmates, and feel more ready for the workforce because of that.

I believe that being able to implement [economic concepts] in daily life is a great skill to have, because just knowing the concepts, in my opinion, is not very beneficial if I am not able to apply them and relate them to real-life situations... Another important point that I got out of this class was that I was encouraged to think critically about many of these agricultural issues and take into consideration all aspects of them... I believe that the skills that I learned in this class will be beneficial for me in the future and in the employment that I seek.

Working in teams can be quite difficult, which it was, but I feel that I really improved my teamwork skills as well as being able to communicate with others better. I also learnt that communication between your peers is important in order to gain more insight and information about a particular problem that is occurring. This was great to get more practice because I was always shy to work with other people. Now I think in my future working years I will be able to be a better team worker and communicate better with colleagues and clients.

The fact that real life events were brought into economics was awesome and such a good way to learn the content. I am definitely a person who learns and understands more when real life relevant events are brought into the classroom. There are many things that I will be taking away from this course. I quite enjoyed this class because of the way I could relate economics to my own life. This is going to be very useful in my future years.

BPBE 272 has taught me essential skills such as communication, research knowledge, and economic theory. This course helped me develop critical thinking skills and communication skills... The assignments in this class were very informative and I learnt a lot from completing them. My perspectives on some of the topics in this course have changed and helped me keep an open mind for economics in the world.

Knowing how to defend your own argument with logic and evidence is something that I will have to do when I get into my career. Having the knowledge of how economic theory is actually applied to a real life situation will be greatly beneficial. Thinking at a margin will help solve 
not just economic issues, but any issues that may come up in the workplace. Using this information and skills will help me get and do well in my chosen career.

I have learned how to be more open-minded when discussing issues I have a very strong opinion on. Using all these things I have learned from this class will help me be a better student for the rest of my university career and it will help me be a better professional. I believe more classes should use this style of learning as I will retain and remember all of the things I have learned and carry them forward with me into the future.

I liked that the class was given the chance to decide on the winner of each debate as a whole, because it forced us to sit back and objectively listen to all the facts before making a biased decision.

I really appreciated the way you taught this class. This class was so different than any other class I have taken at university so far... I can say that I for sure came out of this class being able to actually relate what I learnt to real life situations and that I will actually remember the information that was taught to me. Another great aspect about this teaching style is that teamwork and group work is key... Having the skill of being able to work and cooperate with other is a skill that will take you far in life no matter what you are doing. The group work in this class allowed us to not only to communicate and make group decisions but also had us doing real life organizations skill while trying to make time to meet with the group.

The above responses to the open-ended question demonstrate the power of coaching in the classroom. Hesseln, as the instructor using a coach approach based on insight and innovative teaching methods, delivered in an authentic manner, created an engaged atmosphere that encouraged students to be present and mindful, and to learn from each other. Additionally, empowering students to take charge of their own learning and to practice skills in a supportive and open classroom enlightened them to future possibilities, thus helping them to articulate clear personal visions.

One of the most important results was that students not only learned economic theory and its applicability, but they learned the importance of how to relate their education to the workforce and to hone essential skills such as communication, critical thinking, collaboration, and continuous learning.

\section{The power of coaching}

Executive coaching has fast risen as a necessary and crucial component of business to promote career and personal success, wellbeing, employee and 
customer satisfaction, learning outcomes, leadership skills, and overall productivity. Additionally, coaching is highly effective in creating engaged employees and enhancing essential skills such as effective communication, collaboration, critical and creative thinking, and continuous learning. In addition to using coaching in the workplace, we suggest that using a coach approach during postsecondary education in programs that focus on training (e.g. applied programs, business, etc.) can inspire students to learn more effectively and to empower them to see the value of life-long learning.

Coaching encourages students and lecturers to interact in a positive manner and to foster enhanced learning outcomes in the classroom. Additionally, students realize greater research potential as a result of heightened curiosity and positive inquiry. Coaching helps to develop everyone in academic organizations in ways that create increased individual, team, and organizational performance, and ultimately, shared value. What better way to bridge the gap between academia and the labour market?

Our paper synthesizes eclectic research from psychology, pedagogy, business and leadership to construct a model to enhance teaching and learning at the postsecondary education level. While much of the research shows each element to be successful as a pedagogical approach, further research is required to evaluate the process as a whole. Future research should examine more critically the effects of coaching on learning outcomes, educational tools and approaches to empowering students, lesson retention, and labour market outcomes for students who have experienced a coach approach in academia.

\section{References}

Ashkanasy, N. M., \& Tse, B. (2000). Transformational leadership as management of emotion: A conceptual review. In Ashkanasy, Neal M., Härtel, Charmine E., Zerbe, Wilfred J. (Eds). Emotions in the workplace: Research, theory, and practice (pp. 221-235). Westport, CT: Quorum Books/Greenwood Publishing Group

Askew, J. (no date). Authentic Learning/Teaching/Assessment. Retrieved from http://crescentok.com/staff/jaskew/isr/education/authentic.htm

Bakker, A.B. (2011). An evidence-based model of work engagement. Current Directions in Psychological Science, 20(4): 265-269. http://dx.doi.org/10.1177/0963721411414534

Brown, L. (2016, February 22). Young graduates need to brush up on 3 Rs, employers say. Toronto Star, Retrieved from 
https://www.thestar.com/yourtoronto/education/2016/02/22/younggrads-need-to-brush-up-on-3-rs-employers-say.html

Černe, M., Jaklič, M., \& Škerlavaj, M. (2013). Authentic leadership, creativity, and innovation: A multilevel perspective. Leadership, 9(1) 63-85. http://dx.doi.org/10.1177/1742715012455130

Coutu, D. \& Kauffman, C. (2009). What can coaches do for you? Harvard Business Review, 87(1) 91-97.

Dishman, L. (2016, June 28). These are the biggest skills that new graduates lack. Fast Company Report. Retrieved from http://www.fastcompany.com/3059940/the-future-of-work/these-arethe-biggest-skills-that-new-graduates-lack

Hisschemöller, M., \& Cuppen, E. (2015). Participatory assessment: tools for empowering, learning and legitimating. J. Jordan and J. R. Turnpenny (eds). The Tools of Policy Formulation. ElgarOnline. http://dx.doi.org/10.4337/9781783477043.00013

Human Capital Institute. (2014, December). Building a coaching culture. Human Capital Institute Report.

International Coach Federation (No date). Core Competencies. Retrieved from http://coachfederation.org/credential/landing.cfm? ItemNumber $=2206$

Jacoby, B. (2003). Building Partnerships for Service-Learning, Barbary Jacoby and Associates (eds). San Francisco: Jossey-Bass.

Jandciu, E., Stewart, J. J., Stoodley, R., Birol, G., Han, A., and Fox, J. A. (2015). Bridging the Gap: Embedding Communication Courses in the Science Undergraduate Curriculum. Journal on Excellence in College Teaching, 26(4) 103-123.

Kirk, C. M., Lewis, R. K., Brown, K., Karibo, B., \& Park, E. (2016). The power of student empowerment: Measuring classroom predictors and individual indicators. The Journal of Educational Research, 1-7. http://dx.doi.org/10.1080/00220671.2014.1002880

Kolb, D. A. (2014). Experiential learning: Experience as the source of learning and development. FT press.

Kreber, C. (2013). Authenticity in and through teaching in bigher education: The transformative potential of the scholarship of teaching. Routledge.

Kreber, C., \& Klampfleitner, M. (2012). Construing the meaning of authenticity in university teaching: Comparing explicit to implicit theories. Journal of Constructivist Psychology, 25(1), 34-69. http://dx.doi.org/10.1080/10720537.2012.629114

Kuh, G.D., (2003). What we're learning about student engagement from NSSE: Benchmarks for effective educational practices. Change: The 
Magazine of Higher Learning, 35(2), 24-32.

http://dx.doi.org/10.1080/00091380309604090

Lane, J. \& Scott, M.T. (2015). Smarten up, it's time to build essential skills. Canada West Foundation.

Laud, R.L. \& M. S. Johnson (2013). Progress and regress in the MBA

curriculum: The career and practice skills gap. Organization

Management Journal, 10(1), 24-35.

http://dx.doi.org/10.1080/15416518.2013.781398

Lord, T. (2007). Revisiting the cone of learning - is it a reliable way to link instruction method with knowledge recall? Journal of College Science Teaching, 37(2), 14-17.

Munter, J. (2002). Linking community and classroom in higher education: Service-learning and student empowerment. Journal of Nonprofit es Public Sector Marketing, 10(2), 151-164. http://dx.doi.org/10.1300/J054v10n02_09

Newmann, F.M. \& Wehlage, G.G. (1993). Five standards of authentic instruction. Educational leadership, 50(7), 8-12.

Newmann, F.M., King, M.B., \& Carmichael, D. L. (2007). Authentic instruction and assessment: Common standards for rigor and relevance in teaching academic subjects. Iowa Department of Education. Retrieved from https://www.centerforaiw.com/wpcontent/uploads/2016/05/authentic-instruction-assessmentbluebook.pdf

Pike, G.R., Kuh, G.D., \& McCormick, A.C. (2011). An investigation of the contingent relationships between learning community participation and student engagement. Research in Higher Education, 52(3), 300-322. http://dx.doi.org/10.1007/s11162-010-9192-1

PriceWaterhouseCoopers. 2014. ICF Global Consumer Awareness Study. PwC's International Survey Unit, Price WaterhouseCoopers LLP.

Rappaport, J. (1981). In Praise of Paradox: A Social Policy of Empowerment Over Prevention, American Journal of Community Psychology, 9(1), 1. http://dx.doi.org/10.1007/BF00896357

Sabatier, M. (2015). Why executive coaching is back in vogue. Training Journal, 16 February. Retrieved from: https:/www.trainingjournal.com/articles/feature/why-executivecoaching-back-vogue

Savery, J.R. \& Duffy, T.M. (1995). Problem based learning: An instructional model and its constructivist framework. Educational technology, 35(5), 31-38. 
Singh, M.D., Pilkington, F.B., \& Patrick, L. (2014). Empowerment and mentoring in nursing academia. International journal of nursing education scholarship, 11(1), 101-111. http://dx.doi.org/10.1515/ijnes-2013-0070

Thompson, H.B., Bear, D.J., Dennis, D.J., Vickers, M., London, J., \& Morrison, C.L. (2008). Coaching: A global study of successful practices: Current trends and future possibilities, 2008-2018. New York: American Management Association.

Whittington, J. L., \& Galpin, T.J. (2010). The engagement factor: building a high-commitment organization in a low-commitment world. Journal of Businesd Strategy, 31(5), 14-24. http://dx.doi.org/10.1108/02756661011076282

Wicks, D. (No date). What are the causes of poor workplace communication? Houston Chronicle. Retrieved from http://smallbusiness.chron.com/causes-poor-workplacecommunication-20827.html 